\title{
Patient satisfaction is biased by renovations to the interior of a primary care office: $a$ pretest-posttest assessment
}

\author{
Raphaël Tièche ${ }^{1}$, Bruno R. da Costa $^{2}$ and Sven Streit ${ }^{2^{*}}$ (D)
}

\begin{abstract}
Background: Measuring quality of care is essential to improve primary care. Quality of primary care for patients is usually assessed by patient satisfaction questionnaires. However, patients may not be able to judge quality of care without also reflecting their perception of the environment. We determined the effect that redesigning a primary care office had on patient satisfaction. We hypothesized that renovating the interior would make patients more satisfied with the quality of medical care.

Methods: We performed a Pretest-Posttest analysis in a recently renovated single-practice primary care office in Grenchen, Switzerland. Before and after renovation, we distributed a questionnaire to assess patient satisfaction in four domains. We chose a Likert scale $(1=$ very poor to $6=$ very good $)$, and 12 quality indicators, and included two consecutive samples of patients presenting at the primary care office before $(n=153)$ and after $(n=153)$ interior design renovation.

Results: Response rate was high (overall $85 \%$ ). The sample was similar to the enlisted patient collective, but the sample population was older (60 years) than the collective (52 years). Patient satisfaction was higher for all domains after the office was renovated $(p<0.01-0.001)$. Results did not change when we included potential confounders in the multivariable model $(p<0.01)$.

Conclusions: Renovating the interior of a primary care office was associated with improved patient satisfaction, including satisfaction in domains otherwise unchanged. Physician skills and patient satisfaction sometimes depend on surrounding factors that may bias the ability of patients to assess the quality of medical care. These biases should be taken into account when quality assessment instruments are designed for patients.
\end{abstract}

Keywords: Patient satisfaction, Primary care, Quality of care, and Change of appearance

Abbreviations: Cl, Confidence Interval; GP, General Practitioners; MFE, Swiss Occupational Union of General Practitioners and Pediatricans; SD, Standard Deviation

\section{Background}

Measuring quality of care is essential to improve primary care, but measuring quality of care is difficult and there is, as yet, no established method to effectively assess quality [1]. We cannot know what to change unless we know what is wrong. In Switzerland, the concept of quality in primary care is being elaborated by a task force established by the occupational union (MFE) of

\footnotetext{
* Correspondence: sven.streit@biham.unibe.ch

${ }^{2}$ Institute of Primary Health Care (BIHAM), University of Bern,

Gesellschaftsstrasse 49, 3012 Bern, Switzerland

Full list of author information is available at the end of the article
}

general practitioners (GPs) [2]. The concept includes four topics: quality circles (working groups of GPs), patients, health care providers, and the next generation of GPs.

Quality of primary care for patients is usually assessed by patient questionnaires and comparative benchmarks of scores for GP offices, but questionnaires are designed to measure the patient's subjective perception of quality. Conclusions based solely on subjective quality of care assessments by patients may bias results, and limit their usefulness as benchmarks for primary care offices. For example, a recent study shows how difficult it is to 
separate the role of the physical environment from the effect of social forces on patient wellbeing [3].

An earlier UK study found that upgrading the primary care environment can increase patient satisfaction [4]. This and similar studies found that environmental upgrades also improve patient perceptions about the health care they receive $[5,6]$. Patients may not be able to judge quality of care without also reflecting their perception of the environment. On the other hand, Gosling et al. conducted two studies that suggest that observer impressions are often accurate and rely on valid environmental clues to correctly judge the characteristics of staff and other room occupants [7]. Since patients are usually not well-informed about standards of practice, and because they do not have a medical education, they often judge a doctor's performance based on the personality of the physician, and the physical environment [8]. Patients may believe that a redesign reflects the provider's desire to care for their wellbeing, and may then assume that the provider puts the same energy into providing medical services. This may be why attractive and comfortable waiting rooms, and good lighting can result in higher quality of care assessments from patients [9]. Patient assessment of quality of care may not describe accurately the standards of the medical practitioners who treat them.

We hypothesized that upgrading the interior design of an office would improve patient perceptions of quality of care, absent any other changes. We tested our hypothesis with pre- and post-renovation questionnaires to measure the amount that renovating a GP office changed patient satisfaction in other dimensions, like quality of treatment or physician reliability.

\section{Methods}

\section{Study design}

This is an observational study with a pretest-posttest assessment design.

\section{Setting}

Our study was conducted in the group practice of two GPs in Grenchen, a city with 17,000 inhabitants, located in the countryside in the northwestern part of Switzerland. The GP office was founded in 1981 by the senior GP; the junior GP joined the practice in 2013. Patients in Switzerland are free to choose their GP. Two out of three patients at office have seen their physicians there for more than 5 years. The patients who visited the office within the last 2 years were mostly women (53\%); mean age was 52 years. Most patients ( $80 \%$ ) speak German.

\section{Population and intervention}

For 6 weeks, from June 23 until August 8, 2014, the practice was renovated. The entry hall, the reception area, the laboratory where patients give blood, the waiting room, the staff room, and the pharmacy were refurnished (Fig. 1). The consultation rooms were not changed. No new working processes or instruments

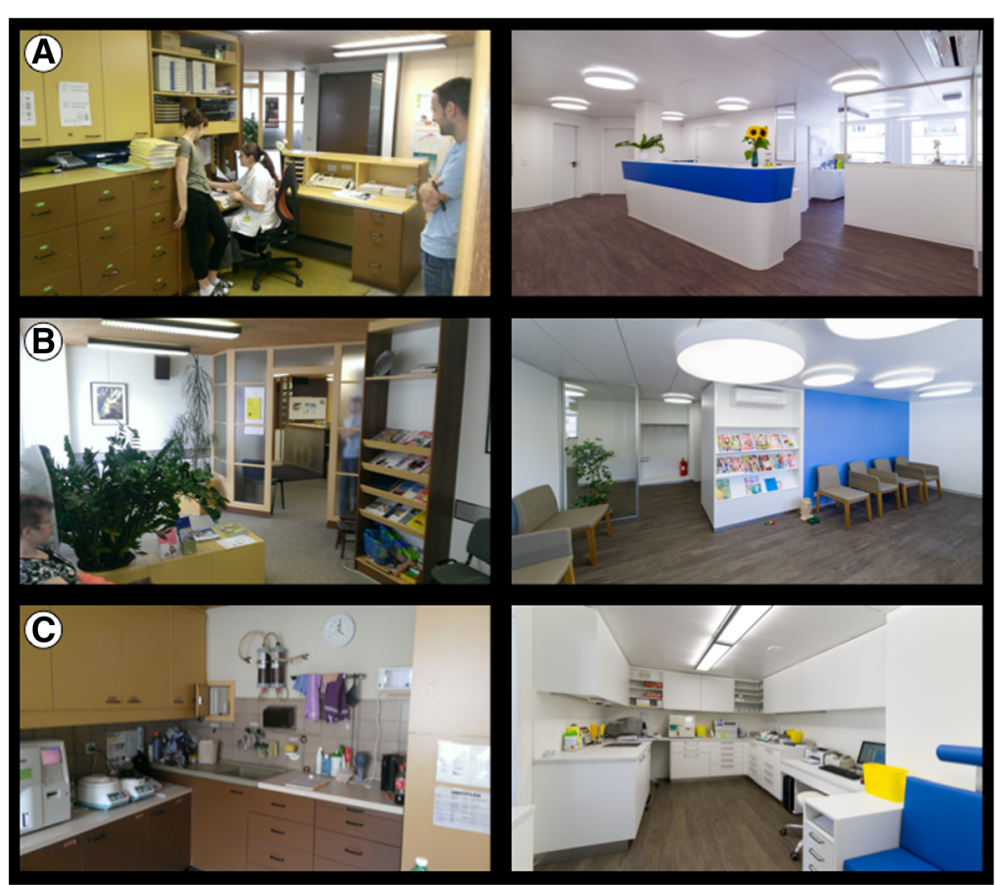

Fig. 1 Panels $\mathbf{a}$, b, and $\mathbf{c}$ display the GP office before (left side) and after renovation (right side). a reception, b waiting room, c laboratory. We received consent to publish the pictures from all people on (a) 
were introduced during the observation period. Both GPs continued working the same number of days before and after renovation (senior GP 3 days/week, junior GP 4 days/week). A medical assistant who had been working 3 days/week left the team after the renovation; four medical assistants remained (3 working full time, 1 working 2.5 days/week). We performed a 1-week pilot study to assess feasibility and reply rate before the renovations began.

On April 7, 2014, while patients were waiting to consult the doctor, a medical assistant assured patients of anonymity and asked for oral consent before she distributed survey questionnaires (Additional file 1). The GPs did not distribute the questionnaire or refer to it during consultation. The questionnaire was offered to all Germanspeaking patients aged $>18$ years, in order of arrival, until all 180 questionnaires were handed out. Patients could fill out the forms before or after they saw the doctor. After the consultation, and before they left the office, a medical assistant asked patients if they had completed the questionnaire and collected them.

The week after renovation, a medical assistant distributed another 180 questionnaires, using the same strategy as for the first. The second questionnaire was the same as the first, but was printed on yellow paper, so patients who had filled it out in the first round would not think they were being given an identical questionnaire. Patients were told this questionnaire would be for post-assessment after renovation and to fill out the questionnaire only if they had already attended the office prior to renovation ( $>2$ months). For post-assessment patients attending the office for $<2$ months, this was an exclusion criteria.

To replicate the sample size of similar surveys done by two Swiss institutes [10, 11], we decided to recruit at least 150 patients for each of the pre- and post-renovation assessments. Based on the pilot assessment, we expected an $80 \%$ or greater response rate, so we handed out 180 survey questionnaires during pre- and post-assessments.

Swiss law on human research (Humanforschungsgesetz, HFG) does not require ethics committee approve to collect and analyze anonymous non-medical data.

\section{Measuring patient satisfaction}

We assessed patient satisfaction by asking patients to grade 12 quality indicators on a Likert scale from 1 (very poor) to 6 (very good). We assessed the following characteristics: 1) appearance of the facility; 2) condition of diagnostic equipment; 3 ) level of hygiene at the practice; 4) punctuality and dependability of the staff; 5) promptness of staff response to patient needs; 6) dress and grooming of the medical assistants; 7) friendliness and courtesy of the medical assistants; 8) attentiveness and responsiveness of the GP to patient needs; 9) GP's perceived level of expertise; 10) GP's level of empathy; 11) overall medical performance of the office; and, 12) overall patient satisfaction with the office (Table 1). We chose these indicators after we performed a literature search to bring our work into accord with published studies [10] and in line with two questionnaires already commonly used to assess patient satisfaction in Switzerland [11, 12]. To interpret the results, we grouped the 12 quality indicators into four domains, each of which covers a specific topic, and then averaged the corresponding items: 1) appearance of the office; 2) qualities of the medical assistants; 3) qualities of the GPs; and, 4) general satisfaction. We used Cronbach's alpha to assess whether items within each of the four groups of quality indicators seemed to measure the same construct (Cronbach's alpha was good, ranging from 0.75 to 0.88$)$.

\section{Statistical analysis}

We used means and standard deviations, or numbers and proportions, for descriptive statistics. We calculated means and $95 \%$ confidence intervals of preand post-assessments for each of the four domains, and then compared them, using linear regression with robust standard errors, so we could account for the possibility some patients were included in both phases of the assessment. We then created multivariable models to control for the potential influence of confounders by simultaneously including the following variables in the model: age, sex, GP assignment, and, duration of assignment. We used STATA release 13.1 for all analyses (Stata Corp, College Station, TX, USA). A $p$-value of $<0.05$ was considered statistical significant.

Table 1 Domains of quality indicators selected to measure patient satisfaction

\begin{tabular}{|c|c|c|}
\hline \multirow{2}{*}{$\begin{array}{l}\text { Domains } \\
\text { Appearance of the office }\end{array}$} & \multicolumn{2}{|c|}{ Quality indicators } \\
\hline & 1 & Appearance of the facility \\
\hline & 2 & Diagnostic equipment \\
\hline & 3 & Level of hygiene \\
\hline & 4 & Punctuality and dependability \\
\hline & 5 & Prompt response to patient needs \\
\hline \multirow[t]{2}{*}{$\begin{array}{l}\text { Qualities of the } \\
\text { medical assistant }\end{array}$} & 6 & $\begin{array}{l}\text { Dress and grooming of the medical } \\
\text { assistants }\end{array}$ \\
\hline & 7 & $\begin{array}{l}\text { Friendliness and courtesy of the } \\
\text { medical assistants }\end{array}$ \\
\hline \multirow[t]{3}{*}{$\begin{array}{l}\text { Qualities of the } \\
\text { general practitioner }\end{array}$} & 8 & $\begin{array}{l}\text { GP is attentive and responsive to } \\
\text { patient's needs }\end{array}$ \\
\hline & 9 & GP's level of expertise \\
\hline & 10 & GP's level of empathy \\
\hline \multirow[t]{2}{*}{ General satisfaction } & 11 & Medical performance of the office \\
\hline & 12 & Overall satisfaction with the office \\
\hline
\end{tabular}




\section{Results}

\section{Baseline characteristics}

A total of 153 (85\%) patients participated in the prerenovation survey; the same number participated in the post-renovation survey (Table 2). We excluded 16 patients in the post-assessment phase because they had attended the office for $<2$ months and had therefore not seen the office prior to renovation. The overall mean age of the study population was $60 \pm 18$ years (SD); of these, $53 \%$ were women. Most patients were seen by the senior GP (53\%), and most patients had attended the practice for over 5 years $(67 \%)$. The patients we included were, on average, about 8 years older than the average of all patients who attended the practice $(60$ years vs. 52 years), probably because we included only patients older than 18.

The groups of patients who filled out the questionnaire before and after renovation were similar in age, sex, and assignment to physicians. The statistical difference in length of assignment to the office resulted from excluding patients who attended for $<2$ months in the post-renovation phase (Table 2).

\section{Patient satisfaction}

Correlations within the four domains were concorded with a Cronbach's alpha between 0.75 and 0.88. Most patients thought the quality of care before renovation was high or very high; most patients graded the characteristics between 5 and 6 in all domains. Figure 2 displays the

Table 2 Basic characteristics of patients before and after renovation

\begin{tabular}{|c|c|c|c|}
\hline Characteristics $^{a}$ & $\begin{array}{l}\text { Before renovation } \\
(n=153)\end{array}$ & $\begin{array}{l}\text { After renovation } \\
(n=153)\end{array}$ & $P$-value \\
\hline \multicolumn{4}{|l|}{ Patients } \\
\hline \multirow[t]{2}{*}{ Age, years (SD) } & $60.9(18)$ & $58.6(18)$ & 0.25 \\
\hline & $n=149$ & $n=151$ & \\
\hline \multirow[t]{2}{*}{ Women, n (\%) } & $78(51)$ & $85(55)$ & 0.56 \\
\hline & $n=149$ & $n=151$ & \\
\hline GP assignment, $\mathrm{n}(\%)$ & & & 0.77 \\
\hline senior GP & $81(53)$ & $79(52)$ & \\
\hline junior GP & $46(30)$ & $47(31)$ & \\
\hline \multirow[t]{2}{*}{ both } & $18(12)$ & $22(14)$ & \\
\hline & $n=145$ & $n=148$ & \\
\hline $\begin{array}{l}\text { Duration of assignment, } \\
\mathrm{n}(\%)\end{array}$ & & & 0.005 \\
\hline$<2$ months & $12(8)$ & $0(0)$ & \\
\hline$<1$ year & $17(11)$ & $27(18)$ & \\
\hline $1-5$ years & $21(14)$ & $18(12)$ & \\
\hline \multirow[t]{2}{*}{$>5$ years } & $101(66)$ & $105(69)$ & \\
\hline & $n=151$ & $n=150$ & \\
\hline
\end{tabular}

a due to missing data the $\mathrm{n}$ of each group is listed beneath each item number of patients and mean values per domain, before and after renovation. Most patients filled out all items on the questionnaire. The lowest response rate (96\%) was for the domain "appearance of the office," and the highest (99 \%) was for the domain "qualities of the medical assistant". Mean values before renovation were similar across all domains. The domain "appearance of the office" had the lowest mean value (5.27; $95 \%$ confidence interval 5.17 to 5.37). Mean value for all domains increased a statistically significant amount after renovation $(p<0.01)$. The largest improvement in patient satisfaction was in the domain "appearance of the office" $(p<0.001)$, though the magnitude of improvement was similar across all domains. For all domains, results were unchanged after we included potential confounders in the multivariable model (Table 3).

\section{Discussion}

Patient satisfaction significantly increased in all domains after the renovation, even though only exterior quality indicators changed. Patient satisfaction with the appearance of the office improved, but so did their satisfaction with office and medical processes, patient management, and other measures like the dress and grooming of medical assistants, and the level of expertise of the GP.

Ulrich RS et al., long ago recognized the impact of visual change on patient satisfaction [13]. In Ulrich's study of hospitalized patients after cholecystectomy in Pennsylvania, USA, those patients assigned to a room with a view of nature were less likely to make negative comments on evaluations. Likewise, Otani $\mathrm{K}$ et al. [14] examined patients in a primary care setting in the US and found that patients looked for surrogate indicators for quality of physician care among the measures available to them. DeLia D et al. [15] interviewed outpatients in New York, USA, to determine which aspects of the ambulatory care visit had the greatest influence on patients' overall site evaluation. In addition to the personal interaction between patients and physicians, and provider continuity, the appearance of the facility was a high priority, which may explain why, in our study, patient perception of quality of care increased in all domains after the clinic was renovated.

\section{Limitations and strengths}

Our study has several limitations and some strengths. Our questionnaire was not validated, but the questions we asked covered the same domains as common questionnaires in Switzerland [10, 11]. We distributed our questionnaire consecutively but they did not include a uniform identification number, so we could not determine if there was overlap between patients in the preand post-assessments. Instead, we used robust regression to account for dependency between the two samples. 

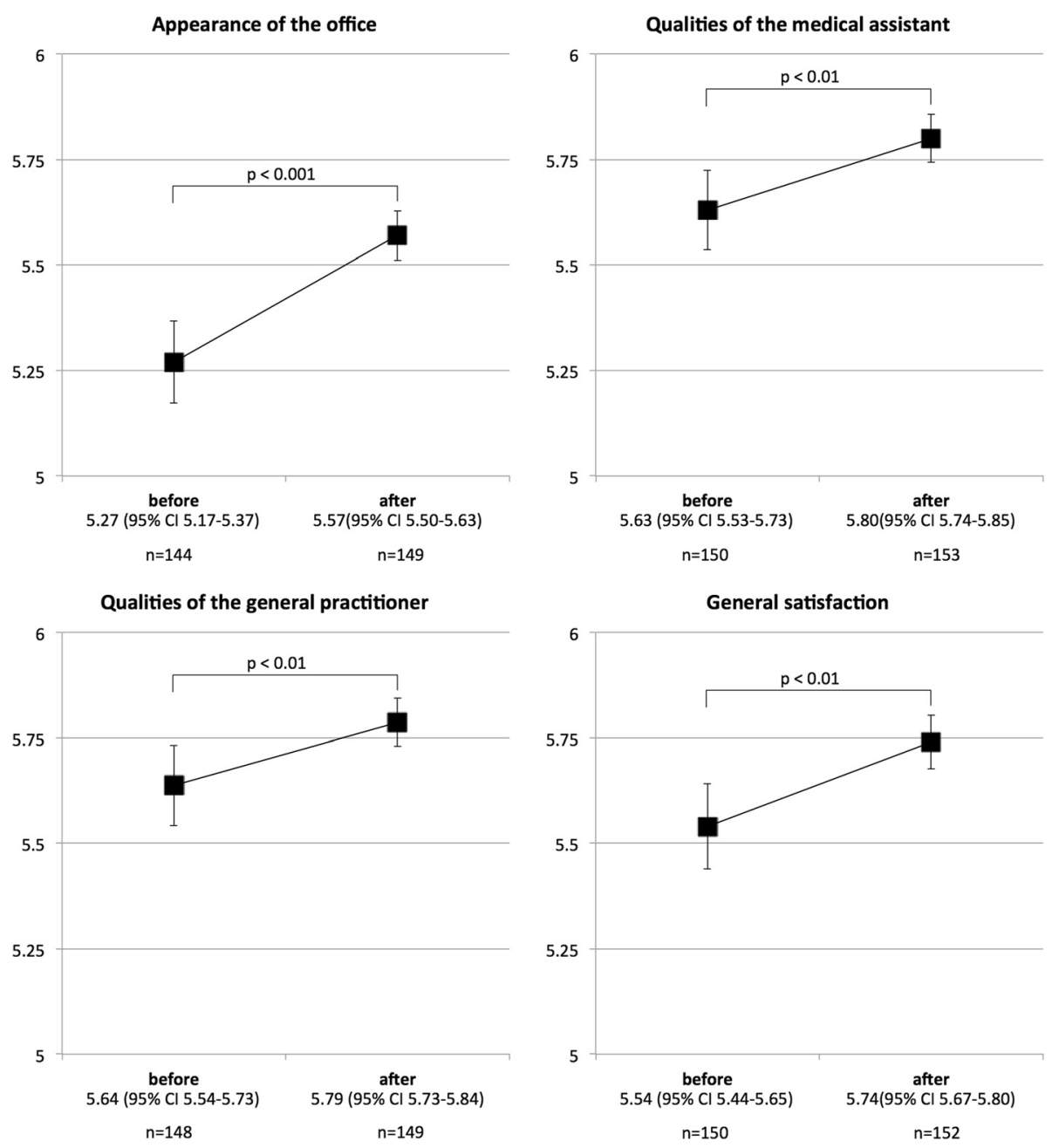

Fig. 2 Patient satisfaction per domain before and after renovation

Our questionnaire was in German, so it self-excluded patients without sufficient German language skills, but $80 \%$ of all enlisted patients were German speakers. Because we included only patients $>18$ years old, the group we sampled was older than the general patient population of the GP office. Our results can thus only be generalized to patients $>18$ years. We did not seek information about patient social class, housing tenure, or amount of education, though these may be related to patient satisfaction
$[16,17]$. Quality measurement depends on many factors. We attempted to limit those factors by changing only the interior of the clinic, and leaving other factors, including staff and processes, intact. We included a sample of patients similar in size to that used by Swiss governmental and non-government institutions to measure patient satisfaction.

Our findings suggest that caution is indicated when interpreting subjective patient satisfaction questionnaires

Table 3 Comparison of patient satisfaction before and after renovation using univariate and multivariate regression models

\begin{tabular}{|c|c|c|c|c|}
\hline \multirow[t]{2}{*}{ Domains } & \multicolumn{4}{|c|}{ Change in satisfaction ${ }^{a}$ after renovation in 4 domains } \\
\hline & Univariate $(95 \% \mathrm{Cl})$ & $P$-value & Multivariate $^{\mathrm{b}}(95 \% \mathrm{Cl})$ & $P$-value \\
\hline Appearance of the office & $0.29(0.17-0.41)$ & $<0.001$ & $0.26(0.14-0.38)$ & $<0.001$ \\
\hline Qualities medical assistant & $0.16(0.06-0.28)$ & 0.003 & $0.17(0.05-0.28)$ & 0.006 \\
\hline Qualities GP & $0.15(0.04-0.26)$ & 0.008 & $0.15(0.04-0.27)$ & 0.01 \\
\hline General satisfaction & $0.20(0.08-0.32)$ & 0.001 & $0.17(0.05-0.29)$ & 0.006 \\
\hline
\end{tabular}

an a scale from 1 (unacceptable) to 6 (very good), thus e.g. 0.26 means an increase by 0.26 on that scale after renovation

badjusted for age, sex, GP assignment, and duration of assignment 
in primary care because patient satisfaction is not objective, and depends on factors beyond simple medical care. Changing the patient's environment can have a very strong effect on a patient's assessment of other domains of quality, biasing the patient's response. Patient questionnaires do evaluate overall patient satisfaction with a GP office at a particular point in time, and can be structured to provide patients with the opportunity to suggest improvements. However, it would be useful to adjust for factors like time since last renovation when interpreting their results, especially if they are used to set and compare benchmarks for GP offices.

Future research should determine if the increase in patient satisfaction after renovation is only a temporary "bounce", in which case we might see satisfaction drop back to pre-renovation levels over time. It would also be useful to know if patient increase in satisfaction with quality of care is also associated with a real improvement in a non-subjective quality of care indicator and if higher satisfaction is more evident in offices with lower initial scores on attractiveness than in offices already considered attractive.

\section{Conclusions}

Patient perceptions of the skills of physicians, and patient satisfaction with topics in different domains depend strongly on outside factors, like renovation, that can bias patient assessment. Our study is in line with the body of research that indicates that improving the interior of a GP office also improves overall patient satisfaction, including in domains where nothing changed, creating biases that must be accounted for when researchers design and analyze questionnaires about quality of care.

\section{Additional file}

Additional file 1: Survey. (DOCX $131 \mathrm{~kb})$

\section{Acknowledgement}

We thank Kali Tal for her editorial assistance.

\section{Availability of data and materials}

The datasets during and/or analyzed during the current study available from the corresponding author on reasonable request.

\section{Authors' contributions}

RT was involved in conception and design of the study, data collection, interpretation of the data and drafting the manuscript. BC was involved in statistics, interpretation of the data and drafting the manuscript. SS was involved in data management, interpretation of the data, statistics and drafting the manuscript. All authors gave final approval of the manuscript.

\section{Competing interests}

Dr. Tièche declares having received fees for consulting on two occasions not related to this study or subject my Novartis and Behringer-Ingelheim in 2015. Dr. Streit was funded in part by the Swiss University Conference and the State Secretariat for Education, Research and Innovation (SUC project P-10).
Consent for publication

We received consent to publish the pictures from all people on Fig. 1.

Ethics approval and consent to participate

Swiss law on human research (Humanforschungsgesetz, HFG) does not require that an ethics committee approve collection and analysis of non-medical and anonymous data.

\section{Author details}

${ }^{1}$ Primary Care Office, Grenchen, Switzerland. ${ }^{2}$ Institute of Primary Health Care (BIHAM), University of Bern, Gesellschaftsstrasse 49, 3012 Bern, Switzerland.

Received: 5 August 2016 Accepted: 10 August 2016

Published online: 11 August 2016

References

1. Saila T, Mattila E, Kaila M, Aalto P, Kaunonen M. Measuring patient assessments of the quality of outpatient care: a systematic review. J Eval Clin Pract. 2008;14(1):148-54. doi:10.1111/j.1365-2753.2007.00824.x.

2. Quality Task Force by the occupational union of GPs, Switzerland, http://www.hausaerzteschweiz.ch/themen/qualitaet, last Access 6 Apr 2016.

3. Andrade CC, Lima ML, Devlin AS, et al. Is it the place or the people? Disentangling the effects of hospitals $\backslash$ physical and social environments on well-being. Environ Behav. 1-25. doi 10.1177/001391651453682.

4. Rice G, Ingram J, Mizan J. Enhancing a primary care environment: a case study of effects on patients and staff in a single general practice. Br J Gen Pract. 2008;58(552):465-70. doi:10.3399/bjgp08X319422.

5. Swan JE, Richardson LD, Hutton JD. Do appealing hospital rooms increase patient evaluations of physicians, nurses, and hospital services? Health Care Manage Rev. 2003;28(3):254-64.

6. Becker F, Sweeney B, Parsons K. Ambulatory facility design and patients' perceptions of healthcare quality. Herd. 2008;1(4):35-54.

7. Gosling SD, Ko SJ, Mannarelli T, Morris ME. A room with a cue: personality judgments based on offices and bedrooms. J Pers Soc Psychol. 2002;82(3):379-98

8. Taylor SE. Health psychology *8th ed. NY: McGraw Hill; 2011.

9. Devin AS. Judging a book by its cover: medical building facades and judgments of care. Environ Behav. V20N10. doi:10.1177/0013916507302242.

10. Riedel M, Neuenschwander P. Qualitätstransparenz in der Hausarztmedizin. Ergebnisse der repräsentativen Befragung. Online publication 2010: http://www.fmh.ch/files/pdf4/Schlussbericht_reprsentative_Evaluation.pdf, last Accessed 6 Apr 2016.

11. European Practice Assessment EUROPEP, Swiss Foundation EQUAM, http://www.equam.ch, last Accessed 6 Apr 2016.

12. Gaspoz JM, Providoli R. Messung der Patientenzufriedenheit in der Arztpraxis - ein zentraler Baustein Ihrer Qualitätssicherung. PrimaryCare. 2012;12(7):111-2.

13. Ulrich RS. View through a window may influence recovery from surgery. Science. 1984;224(4647):420-1.

14. Otani K, Kurz RS, Harris LE. Managing primary care using patient satisfaction measures. J Healthc Manag. 2005;50(5):311-24. discussion 24-5.

15. DeLia D, Hall A, Prinz T, Billings J. What matters to low-income patients in ambulatory care facilities? Med Care Res Rev. 2004;61(3):352-75. doi:10.1177/1077558703257850.

16. Khayat K, Salter B. Patient satisfaction surveys as a market research tool for general practices. Br J Gen Pract. 1994;44(382):215-9.

17. Papanikolaou V, Zygiaris S. Service quality perceptions in primary health care centres in Greece. Health Expect. 2014;17(2):197-207. doi:10.1111/j.1369-7625.2011.00747.x. 